\title{
A Morphometric Study of the Extraocular Muscles
}

\author{
Estudio Morfométrico de los Músculos Extraoculares
}

\begin{abstract}
Eliud Enrique Villarreal-Silva*; José Miguel Hinojosa Amaya*; Juan José Bazaldua Cruz; David Martínez Fernández ${ }^{* * * *}$; Rodrigo Enrique Elizondo-Omaña; \& Santos Guzmán López*
\end{abstract}

VILLARREAL-SILVA, E. E.; HINOJOSA, A. J. M.; BAZALDUA, C. J. J.; MARTÍNEZ, F. D.; ELIZONDO-OMAÑA, R. E. \& GUZMÁN, L. S. A morphometric study of the extraocular muscles. Int. J. Morphol., 31(1):312-320, 2013.

SUMMARY: Extraocular muscles are important references in strabismus surgery and in placement of intraorbital devices. We analyzed extraocular muscles morphometry and possible anatomical variances of 20 orbits. We report the length, width, and points of insertion of the extraocular muscles. No anatomical variations in length, width and points of insertion were found. With regard to the rectus muscles, it was found that the superior rectus and lateral rectus are the longest muscles and that the width difference between the superior and inferior rectus is greater than that between the medial and lateral rectus and that the point of insertion of the rectus muscles has a variable morphology. The superior oblique muscle was smaller in caliber than the inferior oblique, as consistent with previous anatomical studies. Knowledge of the detailed morphology of extraocular muscles is fundamental in strabismus surgery and represents a key factor for the innovation of surgical techniques and orbital procedures.

KEY WORDS: Extraocular muscles; Morphometry; Orbits.

\section{INTRODUCTION}

Extraocular muscles (EOM) are important reference points in surgery and represent the most frequent site of surgical manipulation for the treatment of strabismus (Khan \& Varvares, 2006; Salem \& Qahtani, 2001; Porter et al., 1995). The classic anatomy literature describes the origin of the rectus muscles (superior: SR, inferior: IR, medial: MR and lateral: LR) at the annulus of Zinn, the levator muscle of the upper eyelid (LM), the superior oblique (SO) at the lesser wing of the sphenoid and the inferior oblique (IO) at the anteroinferior portion of the medial wall of the orbit. The point of insertion of the rectus and oblique muscles is found at the ocular globe; the rectus muscles form a spiral around the sclerocorneal limbus (spiral of Tillaux) and the point of insertion of the oblique muscles is found posterior to this point (Porter et al.). The LM of the upper eyelid extends into the levator aponeurosis to a point of insertion outside the globe.

Strabismus surgery involves the resection, recession, tenectomy, or transposition of the EOM. These surgeries present risks of complications, amongst which the most common are: under- or over-correction, anterior segment ischemia, and other rare complications as perforation of the ocular globe and endophthalmitis (Hong et al., 2005). In order to minimize under- or over-correction, appropriate technique is necessary, as is a detailed understanding of the width and specific point of insertion of these muscles. In addition, the relationships that exist between the point of insertion of the EOM with respect to the fovea and optic nerve have been informative for the implantation of transscleral drug delivery devices (TSDDD) (Feng et al., 2005).

Strabismus surgeries, orbital procedure techniques, and the development of intraorbital devices are constantly evolving. Detailed knowledge of EOM morphology and the relationship to other structures is fundamental for related medical innovation. No morphometric studies focusing on the entirety of the EOM were found in the current literature. The purpose of this study was to analyze the morphometric characteristics, relationships, and anatomic variation of the EOM.

\section{MATERIAL AND METHOD}

This is a descriptive, observational, non-comparative study that involved morphometric analysis of the EOM,

\footnotetext{
* Department of Human Anatomy, School of Medicine, Universidad Autónoma de Nuevo León, Monterrey, N.L. México.

** Ophthalmologist
} 
EOM relationships, and possible anatomical variances. Twenty orbital dissections were performed on Mexican embalmed cadavers (age range: 30-60) provided by the Macroscopic Human Anatomy Laboratory of the Universidad Autónoma de Nuevo León School of Medicine.

Orbital content was extracted by way of a superior orbitotomy with a facial and intracranial approach and was subsequently placed in molds with the same dimensions as the orbital cavity in order to facilitate dissection and handling. Dissection of the orbital content was performed in the superior, lateral, medial, and inferior planes using surgical microscopy (Karl Zeiss microscope, 6.0X magnification). The dissection and measurement of the oblique muscles required detachment of the superior and lateral rectus muscles at their origin in the tendinous ring. After this, the following measurements were taken: length, width of the insertion tendon, point of insertion and relationship of insertions of the oblique muscles. Morphometric analysis of the ocular globe was also conducted.

Muscle length (Fig. 1) was defined as the distance between fibers of origin and the middle point of insertion (Length: SR, IR, MR, LR). The length of the SO was measured in two segments: one proximal from the origin to the trochlea (Length: SO Prox) and one distal, which was also measured anteriorly and posteriorly from the trochlea to the point of insertion (Length: SO.Dist.Ant and SO.Dist.Post); the length of the IO was also measured anteriorly and posteriorly from its origin to its insertion (Length: IO.Ant and IO.Post). The length of the LM of the upper eyelid was measured from its origin to the midpoint of the muscular segment immediately prior to the levator aponeurosis (Length: LM).

The width of all the muscles' tendons (Figure 1) was defined as the distance between the insertion of the fibers at each end of the tendon (Width: SR, IR, MR, LR, SO, IO). The exception was the levator muscle of the upper eyelid, where we considered the width of the most distal segment of its muscle belly (Width: LM).

The specific insertion of the EOM (Fig. 2) was determined by measuring the distance between the midpoint of insertion and the most proximal segment of the limbus following the long axis of the ocular globe (insertion: SR, IR, LR, MR, SO, IO). The specific insertion of the LM was excluded from this work because of its point of insertion outside the ocular globe.

The relationships between the superior oblique and the superior rectus and between the inferior oblique and lateral rectus (Figure 3) were determined by measuring the
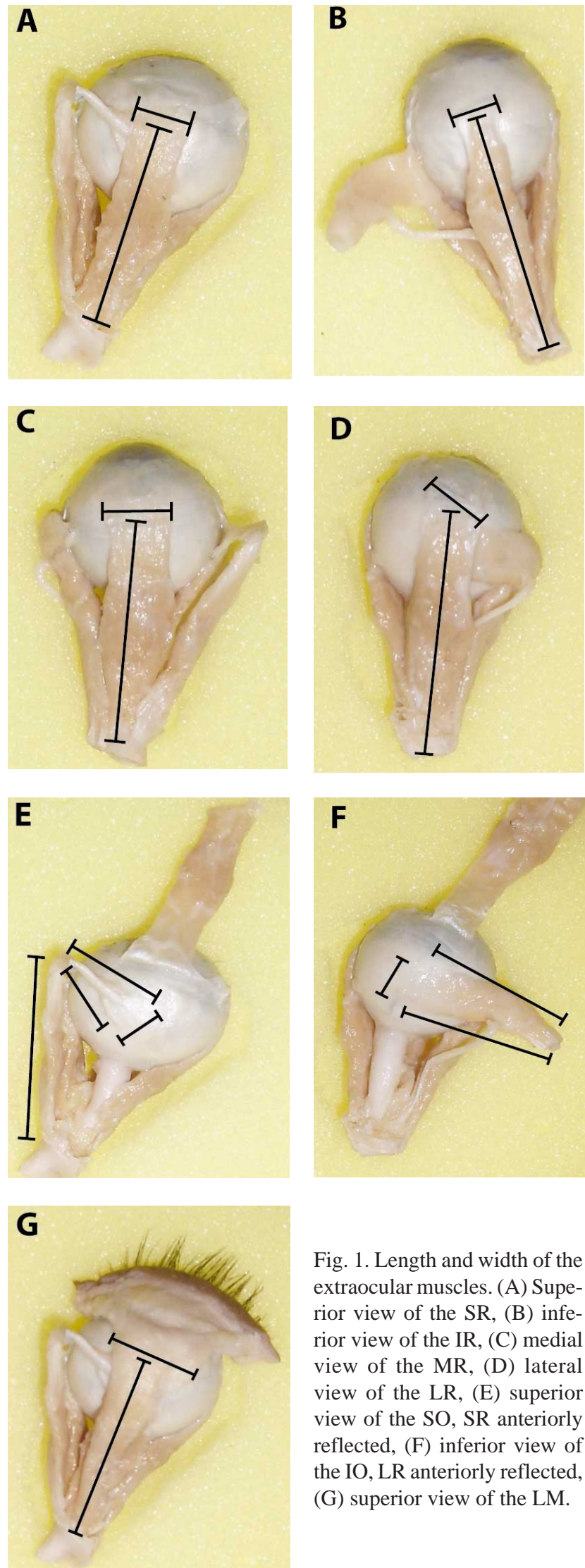

Fig. 1. Length and width of the extraocular muscles. (A) Superior view of the $\mathrm{SR}$, (B) inferior view of the IR, (C) medial view of the MR, (D) lateral view of the $L R$, (E) superior view of the SO, SR anteriorly reflected, (F) inferior view of the IO, LR anteriorly reflected, (G) superior view of the LM. 

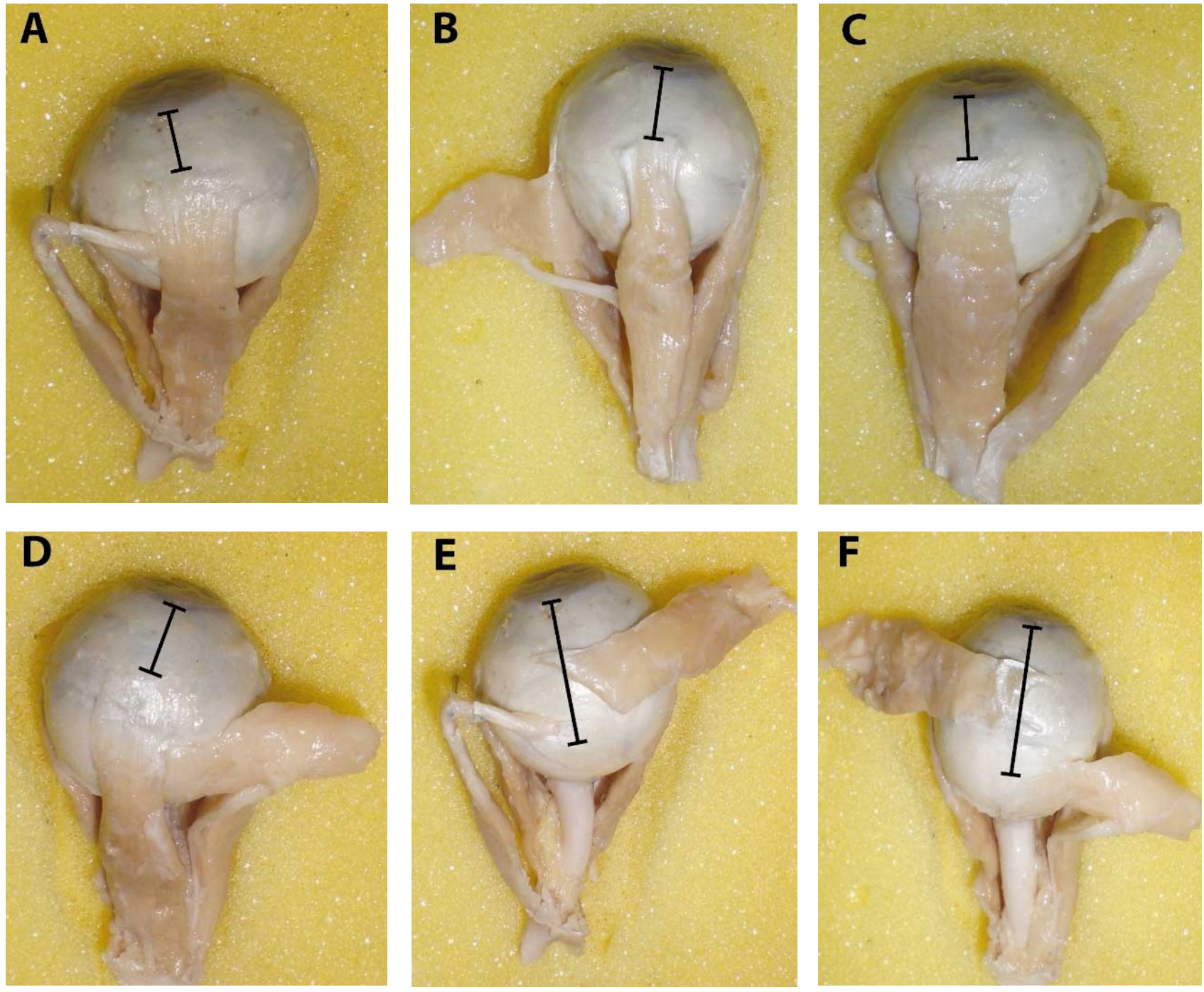

Fig. 2. Point of insertion of the extraocular muscles. (A) Superior view of the SR,(B) inferior view of the IR, (C) medial view of the MR, (D) lateral view of the LR, (E) superior view of the SO, SR laterally reflected, (F) lateral view of the IO, LR reflected in the superior direction.
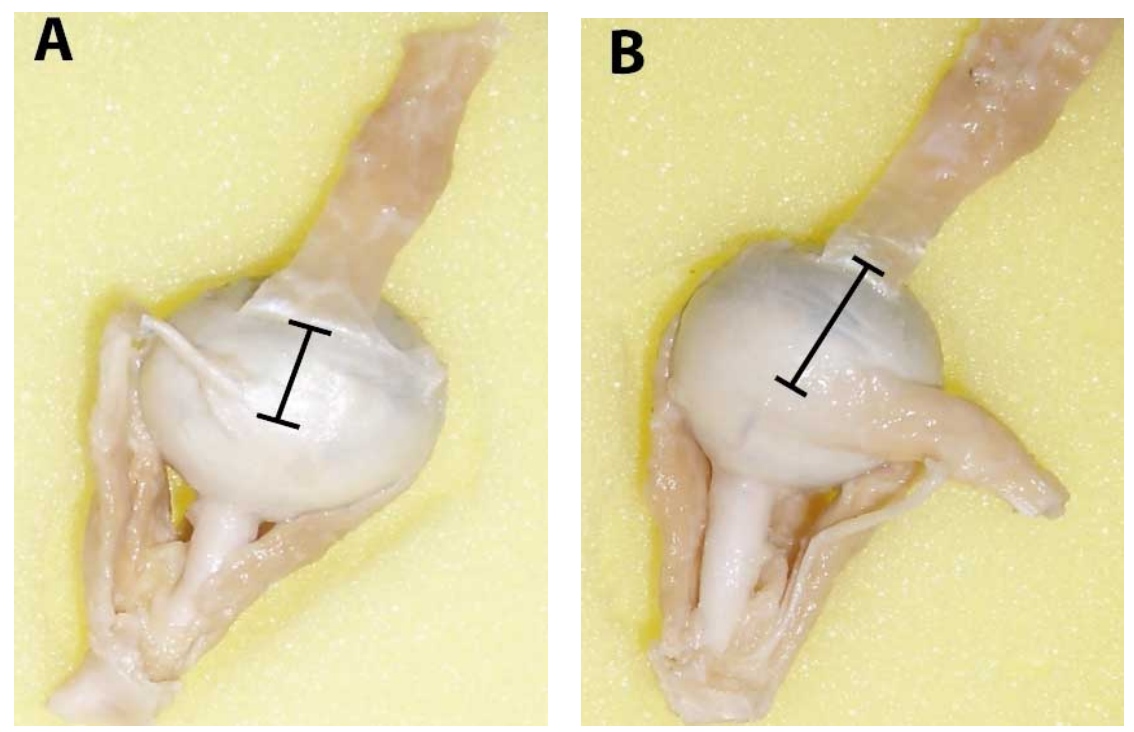

Fig. 3. Relationship between oblique and rectus insertions. (A) Superior view of the orbital content with the SO-SR distance displayed, (B) lateral view of the orbital content with the IO-LR distance displayed. 

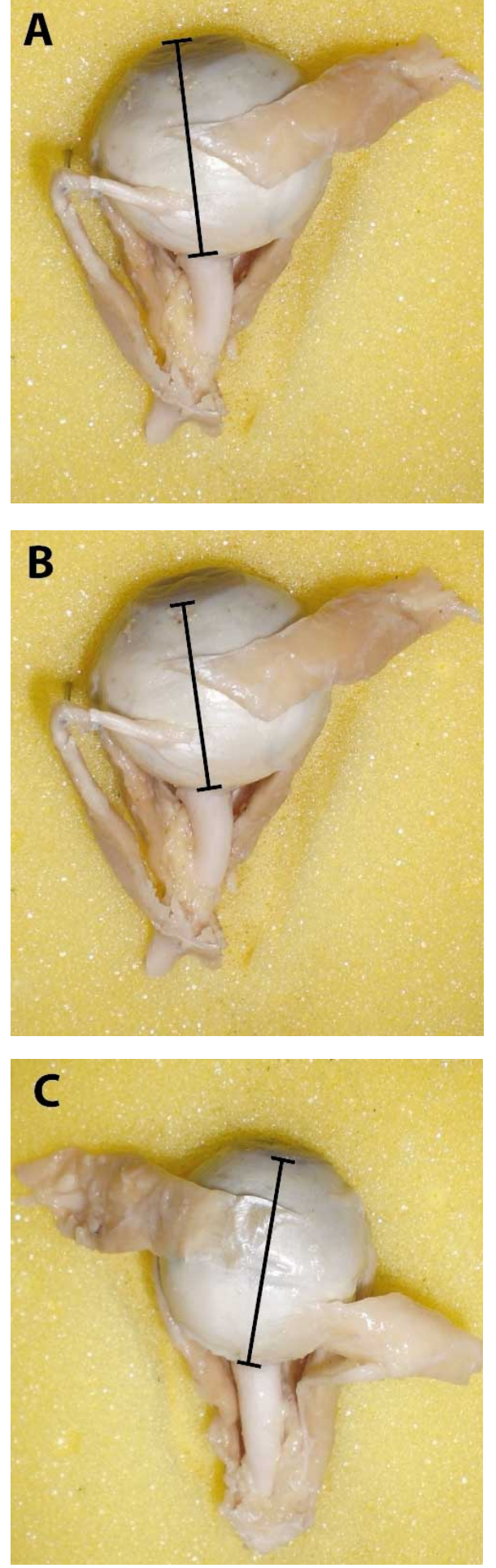

Fig. 4. Morphometry of the ocular globe. (A) Superior view of the globe where the axial length measurement of the ocular globe is observed, (B) superior view of the globe where the C-ON Sup. distance view is observed, (C) Lateral view of the globe where the C-ON Lat. distance is observed. distance between the midpoint of insertion of the oblique muscle and the most proximal fiber of the rectus muscle along the long axis of the ocular globe (SO-SR and IO-LR).

Ocular globe measurements (Fig. 4) were made following the eye's long axis. We measured the distances between the fixation site of the optic nerve to the ocular globe and the following references: the most prominent point of the cornea (Axial length: $\mathrm{AL}$ ), the most superior point to the sclerocorneal limbus (ON-C.Sup) and the most lateral point of the sclerocorneal limbus (ON-C.Lat).

The aforementioned parameters were standardized and measured with a digital vernier (Vernier Fowler Sylvac with 6" / 150 mm, 0.0005" / 0.01 $\mathrm{mm}$ of resolution) using surgical microscopy (Karl Zeiss microscope, 6.0X magnification) by two independent observers, who were blinded to each other's assessments. The results were calculated and analyzed with Microsoft Office Excel 2003, and the mean and standard deviation for each parameter were obtained.

\section{RESULTS}

We analyzed 20 orbits from embalmed cadavers without a history of orbital pathology. The morphology of the EOM included length, width, point of insertion, and relationship of insertions for each of the oblique muscles. For muscle length (Table I), we obtained a measurement for each rectus muscle, as well as proximal segments of the $\mathrm{SO}$ and LM; for the distal segment of the $\mathrm{SO}$ and the $\mathrm{IO}$, we obtained measurements of the anterior and posterior segments of the tendon or muscle.

Table I. Morphometry of extraocular muscles.

\begin{tabular}{lccc}
\hline Muscles & Length $(\mathbf{m m})$ & Width $(\mathbf{m m})$ & Insertion $(\mathbf{m m})$ \\
\hline SR & $37.46 \pm 3.10$ & $8.68 \pm 1.51$ & $7.52 \pm 1.13$ \\
IR & $34.89 \pm 3.54$ & $6.85 \pm .70$ & $6.80 \pm .96$ \\
MR & $35.22 \pm 3.45$ & $8.13 \pm .84$ & $5.99 \pm .80$ \\
LR & $38.81 \pm 3.03$ & $7.76 \pm 1.40$ & $6.77 \pm .61$ \\
SO. Prox & $33.50 \pm 2.44$ & & \\
SO. Dist.Ant & $20.61 \pm 1.98$ & $7.10 \pm 1.47 \mathrm{a}$ & $15.92 \pm 1.20^{\mathrm{a}}$ \\
SO. Dist.Post & $18.25 \pm 2.51$ & & \\
IO. Ant & $27.40 \pm 3.30$ & & \\
IO. Post & $30.08 \pm 3.75$ & $9.23 \pm 0.9^{\mathrm{a}}$ & $17.83 \pm 1.07^{\mathrm{a}}$ \\
LM & $31.63 \pm 3.97$ & $12.94 \pm 2.66$ & - - $^{\mathrm{b}}$ \\
\hline
\end{tabular}

Muscles: SR: superior rectus. LR: lateral rectus. IR: inferior rectus. MR: medial rectus. SO.Prox: proximal segment of the superior oblique. SO.Dist.Ant: anterior segment of the distal superior oblique tendon. SO.Dist.Post: posterior segment of the distal superior oblique tendon. IO.Ant: anterior segment of the inferior oblique muscle. IO.Post: posterior segment of the inferior oblique. LM: levator muscle of the upper eyelid. a Only the width and point of insertion of the distal portion of the tendon were measured. b Insertion were not measured. 
With respect to the width and point of insertion of the tendons (Table I), we obtained independent measurements for each rectus or oblique muscle. For the LM, the width of the muscle belly was obtained; because of its insertion outside the ocular globe, the muscle insertion was not measured. In addition, for each oblique muscle, insertion relationships with the superior or lateral rectus muscle were reported (Table II).

Table II. Relationships for the oblique muscles.

\begin{tabular}{lc}
\hline Parameter & Distance $(\mathbf{m m})$ \\
\hline SO-SR & $9.77 \pm 1.38$ \\
IO-LR & $12.90 \pm 1.17$ \\
\hline
\end{tabular}

Parameter: SO-SR: distance between the midpoint of the superior oblique insertion and the insertion closer to the superior rectus along the long axis of the globe. IO-LR: distance between the medial point of insertion of the inferior oblique and the most proximal point of insertion of the lateral rectus along the long axis of the ocular globe.
Three measurements were obtained for ocular globe morphometry (Table III): axial length, as well as distance between the fixation point of the optic nerve and the superior and lateral segments of the sclerocorneal limbus.

Table III. Ocular globe measurements.

\begin{tabular}{ll}
\hline Parameter & Mean $(\mathbf{m m})$ \\
\hline AL & $22.87 \pm 1.46$ \\
ON-C.Sup & $21.28 \pm 1.43$ \\
ON-C.Lat & $21.59 \pm 1.26$ \\
\hline
\end{tabular}

Parameter: AL: axial length. distance from the point of fixation of the optic nerve at the ocular globe to the most prominent point of the cornea. ON-C.Sup: distance from the point of fixation of the optic nerve to the ocular globe and the most superior point of the limbus. ON-C.Lat: distance from the point of fixation of the optic nerve to the ocular globe and the most lateral point of the limbus.

Table IV. Insertions of the medial rectus muscle and lateral rectus muscle.

\begin{tabular}{lccc}
\hline Reference & \multicolumn{2}{c}{ Tamburrelli et al. (2003) } & Villarreal (current study) \\
\hline Measurement type & Ultrasound (pre-op) & Direct (intra-op) & Direct (dissection) \\
MR (mm) & $5.61 \pm 0.62$ & $5.46 \pm 0.76$ & $5.9 \pm 0.8$ \\
LR $(\mathbf{m m})$ & $5.76 \pm 0.6$ & $6.25 \pm 0.51$ & $6.77 \pm 0.66$ \\
\hline
\end{tabular}

MR. Medial rectus muscle; LR. Lateral rectus muscle.

Table V. Morphometry of the superior oblique SO-SR: Throw ratio between superior oblique and superior rectus muscle points of insertion.

\begin{tabular}{|c|c|c|c|}
\hline References & \multicolumn{2}{|c|}{ von Noorden (1996) } & Villarreal (current study) \\
\hline Reference Fibers & Anterior fibers & Posterior fibers & Medial Fibers \\
\hline Width (mm) & \multicolumn{2}{|c|}{11} & $7.10 \pm 1.47$ \\
\hline Insertion (mm) & 13.6 & 18.8 & $15.92 \pm 1.20$ \\
\hline SO-SR (mm) & $3.0-4.5^{\mathrm{a}}$ & $13.6^{b}$ & $9.77 \pm 1.38^{\mathrm{c}}$ \\
\hline
\end{tabular}

a Distance between SO anterior fibers and SR lateral fibers. bdistance between SO posterior fibers and SR medial fibers. cdistance between SO medial fibers and the most proximal segment of the SR. along the longitudinal axis of the ocular globe.

Table VI. Morphometry of the inferior oblique muscle.

\begin{tabular}{lccccc}
\hline Reference & Yalcin \& Ozan (2005) & Paik \& Shin (2009) & Feng et al. (2005) & $\begin{array}{c}\text { Villarreal } \\
\text { (current study) }\end{array}$ \\
\hline Sample type & Embalmed & Embalmed & Fresh & $\begin{array}{c}\text { Formaldehyde } \\
\text { immersion }\end{array}$ & $\begin{array}{c}\text { Embalmed } \\
\text { Width }(\mathbf{m m})\end{array}$ \\
No-LR $(\mathbf{m m})$ & Not reported & $9.01 \pm 1.32$ & $9.38 \pm 1.15$ & $9.2 \pm 0.7$ & $9.23 \pm 0.9$ \\
Variations $^{\mathrm{d}}$ & $91.7 \%$ & $9.16 \pm 1.14^{\mathrm{a}}$ & $10.01 \pm 1.47^{\mathrm{a}}$ & $10.5 \pm 1.0 \mathrm{~b}$ & $12.9 \pm 1.17^{\mathrm{c}}$ \\
\hline
\end{tabular}

IO-LR: Relation between the inferior oblique (IO) and lateral rectus (LR). aMeasurements with respect to the anterior border of the IO and the LR. $\mathrm{b}$ distance between the anterior border of the IO and the most inferior point of insertion of the IO and LR. $\mathrm{c}$ distance between the middle point of insertion of the IO and the LR insertion. $d$ variations: double. triple. and quadruple tendons. 
Table VII. Axial length of the ocular globe.

\begin{tabular}{lcc}
\hline Reference & Lee et al. (2009) & Villarreal (current study) \\
\hline AL $(\mathbf{m m})$ & $23.69 \pm 1.16$ & $22.87 \pm 1.46$ \\
\hline AL: Axial length of the globe.
\end{tabular}

AL: Axial length of the globe.

\section{DISCUSSION}

Morphometric measurements of the EOM were performed where length, width, point of insertion, intermuscular relationships and possible anatomical variances were reported. In addition, we obtained measurements of the ocular globe. The obtained information may be of use in strabismus surgery and orbital procedures.

Rectus muscles. The morphology of the rectus muscles has been widely studied in recent years. Recently, the concept of functional pulleys has been proposed, postulating that the perimuscular connective tissue forms a sheath around the rectus muscles and functions as a pulley that modifies the functional origin of the muscle. In addition, it has been established that the rectus muscles have two muscular segments: a global segment, which is inserted onto the ocular globe, and an orbital segment, with its insertion on the connective tissue pulley (Clark et al., 2000; Demer, 2006; Demer, 2007).

The lengths of the rectus muscles vary depending on the state of contraction and ocular globe position. This measurement parameter is of importance in the orbital intraconal approach because it allows us to determine the dimensions of the muscle cone surrounding the ocular globe. Our measurements showed that the LR and SR are the longest muscles, while the MR and IR are the shortest. Thus, we conclude that with the ocular globe in a primary position, the lateral and superior segments of the muscle cone are larger and the space between the SR and LR muscles is greater, rendering the intraconal approach through this space easier and safer.

The width of the rectus muscle insertion is of interest for strabismus surgeries, where the purpose is to weaken or reinforce the function of the rectus muscle. Surgical interventions at the medial and lateral rectus mainly involve the resection of fibers to weaken function, for example, in pediatric (esotropia and exotropia) and adult (incomplete paralysis of cranial nerve VI and fixation in primary position in the paralysis of cranial nerve IV) strabismus surgery. On the other hand, the handling of the superior and inferior rectus muscles commonly involves vertical resections and transpositions, as in the paralysis of cranial nerve VI (Phillips,
2001; Donnahue, 2007). No tendinous width measurements of the rectus muscles were found in the revised literature. Our results for SR and IR width showed a difference of 1.83 $\mathrm{mm}$, in contrast to the difference between the width of the LR and MR, which was smaller $(0.37 \mathrm{~mm})$; this aspect could be relevant during a vertical resection or transposition, where the knowledge of this difference between antagonist tendons could be of significance for the post-operative results.

The insertion of the rectus muscles is a common handling site in the majority of strabismus surgeries. The spiral of Tillaux is located at the spiral-shaped insertion of the rectus muscles, where the MR has the closest insertion to the sclerocorneal limbus and where the IR, LR, and SR insertions progressively become farther apart. Our morphometric measurements partially coincide with the spiral insertion of Tillaux, given that the IR and LR are inserted at a very similar distance to the sclerocorneal limbus. Tamburrelli et al. took measurements of the point of insertion of the MR and LR in patients who were scheduled to undergo strabismus surgery without a previous surgical history. The measurements were obtained pre-operatively by using an ultrasound and directly during the procedure (Table IV). In comparison with the Tamburrelli et al. study, our measurements displayed slight variation, which allows us to assume that ultrasound measurements of other EOM would be similar to direct measurements during surgery or dissection. On the other hand, the observation of the insertions showed that these have varied morphology, with linear, oblique, and semilunar insertions. We may therefore assume that, in the same tendon, there could be fibers inserted at different distances from the sclerocorneal limbus. As a result, specific measurements of each tendinous segment could provide even greater detail for morphologic study of the insertion of rectus muscles.

Superior oblique muscle. The anatomy of the SO is of upmost importance in those procedures involving the handling of its insertion tendon, for example, a posterior tenectomy for over-function of the SO or transposition in cranial nerve III paralysis (Phillips; Sharma et al., 2005). With respect to posterior tenectomy, it is known that it is a complex procedure with unpredictable results, mainly due to the 
difficulty in accessing its tendon and because of its proximity to the vortex vein (Saxena et al., 2007). Literature review revealed morphometric analysis of the distal segment of the $\mathrm{SO}$, which provided the width and insertion references of the anterior and posterior fibers of the distal tendon with respect to the medial and lateral portions of the SR and the sclerocorneal limbus (von Noorden) (Table V). The width of the SO reported by von Noorden is greater than that found in our study, but the relationships of insertion cannot be compared because the measured parameters are not exactly the same. However, our results contribute information that could be considered during a surgical procedure on this muscle.

Inferior Oblique muscle. The IO is the only oculomotor muscle that does not originate from the orbital vertex. Surgeries of this muscle involve weakening or transposition (for example, in patients with paralysis of cranial nerve IV) (Phillips). Recently, the IO has gained importance in the placement of TSDDD (Feng et al.).

Detailed knowledge of IO morphology is useful in surgeries that involve its manipulation. The anatomy of the distal segment of this muscle has been recently studied (Table VI). Yalcin \& Ozan reported divided insertion tendons in $91.7 \%$ of the IO studied, which were obtained from embalmed cadavers. Paik \& Shin also studied the muscle's width, insertion variables and its relationship with the LR of the IO in fresh and embalmed cadavers. Divided tendons were found in $45 \%$ of the embalmed cadavers but in none of the fresh cadavers. Our study did not find any divided tendons; however, our results are in agreement with those reported by Paik \& Shin regarding tendon width of the IO in fresh cadavers. It is probable that the desiccation state of the embalmed cadavers used in the first two studies resulted in separation of the tendons and insertions. The relationship between the IO and LR reported by some authors cannot be directly compared with our results, as different measurement parameters were used. However, our reports further enrich the anatomical knowledge of this relationship.

The TSDDD represent a therapeutic option for diabetic maculopathy and age-related macular degeneration5. The references of the fovea with respect to the optic nerve, lateral rectus, and inferior oblique are used for TSDDD implantation. Feng et al., (Table VI) reported measurements regarding these relationships. The results of our study provide more information with respect to the existing relationships between the IO, LR, and optic nerve.

Levator muscle of the upper eyelid. The LM is not an oculomotor muscle. With its origin at the orbital vertex, and its continuation with the aponeurosis of the levator, it becomes one of the largest and most complex extraocular muscles. Congenital or acquired blepharoptosis may be surgically treated with procedures that manipulate the anatomy of the LM, for example, the Müller muscle conjunctival resection (IIjin et al., 2007; Georgescu et al., 2009). Recent studies show that the distal segment of the LM is divided in two muscle bellies: one superior that is inserted at the aponeurosis of the levator and one inferior that continues with the Müller muscle (Kakizaki et al., 2009). Study of the distal segment of the LM is outside the scope of this study; however, the reported measurements of the proximal segment establish a basis for future morphometric research of the distal segment of the LM. A better understanding of the LM anatomy could lead to improvement of procedural outcomes involving this muscle.

Muscle variations. The possible anatomical variations of the EOM are of great importance because they must be adequately considered during surgical interventions. Great variations in EOM are rare (Pimanides et al., 2005). In relation to the lesser variations at the level of muscular insertion, there are other studies that report divided tendons in the IO (Yalcin \& Ozan; Paik \& Shin). In this study, there were no such variations in the IO or in any other EOM. These variations at the point of insertion are probably a result of inadvertent dissection of the tendinous fibers or to the desiccated state of the studied specimens.

Ocular Globe. Orbital anatomy variations between ethnic groups have been well recognized (Blake et al., 2003). Knowing the size of the ocular globe allows us to have a reference regarding the possible morphometric variations of the EOM. The axial length of the ocular globe was studied by Lee et al. (2009) (Table VII). The study showed that ocular dimension variations by age and sex are partially explained by differences in height and years of education. We may therefore conclude that slight width and insertion variations of the EOM may also be partially explained by differences in individual height. Our study did not gather data regarding height and education level, thus it is not possible to confirm whether there is a relationship among height, axial length of the globe and EOM morphology. The distance between the optic nerve and the most superior and lateral points of the sclerocorneal limbus provided the most informative reference for the points of insertion of the SO and IO.

This morphometric study of the length, width, insertion, and relationships of EOM insertion provided information that should be considered in strabismus surgery and orbital procedures. In the rectus muscles, we found that the SR and LR are the largest muscles; the width difference between the SR and IR is greater than that between the MR 
and LR; and the point of insertion of the rectus muscles has a variable morphology. In the oblique muscles, we found that the width of the SO is smaller in relation to other references and that the morphology of the IO complements is similar to that previously reported. We did not find anatomical variations in the EOM. The axial length of the ocular globe served as a reference to determine the size of the ocular globes studied.

Finally, it is important to continue discovering new relationships and observations that improve the morphological and functional understanding of the EOM and simultaneously promote the innovation of surgical techniques and procedures related to these muscles.

\section{ACKNOWLEDGEMENTS}

Funding/Support by the Department of Human Anatomy of the Universidad Autónoma de Nuevo León, School of Medicine.

VILLARREAL-SILVA, E. E.; HINOJOSA, A. J. M.; BAZALDUA, C. J. J.; MARTÍNEZ, F. D.; ELIZONDO-OMAÑA, R. E. \& GUZMÁN, L. S. Estudio morfométrico de los músculos extraoculares. Int. J. Morphol., 31(1):312-320, 2013.

RESUMEN: Los músculos extraoculares son importantes en la cirugía de estrabismo y en la colocación de dispositivos intraorbitarios. Analizamos la morfometría de los músculos extraoculares y las posibles variaciones anatómicas en 20 orbitas. No encontramos variantes en longitud, anchura y sitios de inserción. Los músculos rectos superior y lateral son los mas largos; la diferencia en longitud entre los músculos rectos superior e inferior es mayor a la diferencia en longitud entre los músculos rectos medial y lateral. El músculo oblicuo superior es mas pequeño en calibre que el músculo oblicuo inferior, lo que coincide con otros estudios anatómicos. El conocimiento detallado de la morfología de los músculos extraoculares es fundamental en la cirugía de estrabismo y representa un factor clave para la innovación de técnicas quirúrgicas y procedimientos en la cavidad orbitaria.

\section{PALABRAS CLAVE: Músculos extraoculares; Morfometría; Órbitas.}

\section{REFERENCES}

Blake, C. R.; Lai, W. W. \& Edward, D. P. Racial and ethnic differences in ocular anatomy. Int. Ophthalmol. Clin., 43(4):9$25,2003$.

Clark, R. A.; Miller, J. M. \& Demmer, J. L. Three-dimensional location of human rectus pulleys by path inflections in secondary gaze positions. Invest. Ophthalmol. Vis. Sci., 41(12):3787-97, 2000.

Demer, J. L. Evidence supporting extraocular muscle pulleys: refuting platygean view of extraocular muscle mechanics. $J$. Pediatr. Ophthalmol. Strabismus, 43(5):296-305, 2006.

Demer, J. L. Mechanics of the orbita. Dev. Ophthalmol., 40:132157, 2007.

Donnahue, S. P. Clinical practice. Pediatric strabismus. N. Eng. J. Med., 356(10):1040-7, 2007.

Feng, X.; Pilon, K.; Yaacobi, Y. \& Olsen, T. W. Extraocular muscle insertions relative to the fovea and optic nerve: humans and rhesus macaque. Invest. Ophthalmol. Vis. Sci., 46(10):3493-6, 2005.

Georgescu, D.; Epstein, G.; Fountain, T.; Migliori, M.; Mannor, G. \& Weinberg, D. Müller muscle conjunctival resection for blepharoptosis in patients with poor to fair levator function. Ophthalmic Surg. Lasers Imaging, 40(6):597-9, 2009.
Hong, S.; Chang, Y. H.; Han, S. H. \& Lee, J. B. Effect of full tendon transposition augmented with posterior intermuscular suture for paralytic strabismus. Am. J. Ophthalmol., 140(3):477-83, 2005.

Iljin, A.; Zielinska, A.; Karasek, M.; Zielinski, A. \& Omulecka, A. Structural abnormalities in the levator palpebrae superioris muscle in patients with congenital blepharoptosis. Ophthalmic Surg. Lasers Imaging, 38(4):283-9, 2007.

Kakizaki, H.; Prabhakaran, V.; Pradeep, T.; Malhotra, R. \& Selva, D. Peripheral branching of levator superioris muscle and Müller muscle origin. Am. J. Ophthalmol., 148(5):800-3, 2009.

Khan, A. \& Varvares, M. A. Traditional approaches to the orbit. Otolaryngol. Clin. N. Am., 39(5):895-909, 2006.

Lee, K. E.; Klein, B. E.; Klein, R.; Quandt, Z. \& Wong, T. Y. Age, stature, and education associations with ocular dimensions in an older white population. Arch. Ophthalmol., 127(1):88-93, 2009.

Paik, D. J. \& Shin, S. Y. An anatomical study of the inferior oblique muscle: the embalmed cadaver vs the fresh cadaver. Am. J. Ophthalmol., 147(3):544-9, 2009.

Phillips, P. H. Strabismus surgery in the treatment of paralytic strabismus. Curr. Opin. Ophthalmol., 12(6):408-18, 2001. 
VILLARREAL-SILVA, E. E.; HINOJOSA, A. J. M.; BAZALDUA, C. J. J.; MARTíNEZ, F. D.; ELIZONDO-OMAÑA, R. E. \& GUZMÁN, L. S. A morphometric study of the extraocular muscles. Int. J. Morphol., 31(1):312-320, 2013.

Pimanides, D.; Young, S.; Minty, I. \& Spatt, J. Familial aplasia of the inferior rectus muscles. J. Pediatr. Ophthalmol. Strabismus, 42(4):222-7, 2005.

Porter, J. D.; Baker, R. S.; Ragusa, R. J. \& Brueckner, J. K. Extraocular muscles: basic and clinical aspects of structure and function. Surv. Ophthalmol., 39(6):451-84, 1995.

Salem, M. \& Qahtani, F. Risk factors associated with complications of orbital surgery in children. J. Pediatr. Ophthalmol. Strabismus, 38(6):335-9, 2001.

Saxena, R.; Sinha, A.; Sethi, H. \& Menon, V. Trypan blue-assisted posterior tenectomy of the superior oblique. J. Pediatr. Ophthalmol. Strabismus, 44(1):45-6, 2007.

Sharma, P.; Saxena, R.; Rao, B. V. \& Menon, V. Effect of posterior tenectomy of superior oblique on objective and subjective torsion in cases of superior oblique overaction. J. Pediatr. Ophthalmol. Strabismus, 42(5):284-9, 2005.

Tamburrelli, C.; Salgarello, T.; Vaiano, A. S.; Scullica, L.; Palombi, M. \& Bagolini, B. Ultrasound of the horizontal rectus muscle insertion sites: implications in preoperative assessment of strabismus. Invest. Ophthalmol. Vis. Sci., 44(2):618-22, 2003.

von Noorden, G. K. Summary of gross anatomy of extraocularmuscles in: binocular vision and ocular motility. Theory and management of strabismus. St. Louis, MO, Mosby, 1996. pp.41-52.

Yalcin, B. \& Ozan, H. Insertional pattern of the inferior oblique muscle. Am. J. Ophthalmol., 139(3):504-8, 2005.
Correspondence to:

Rodrigo E. Elizondo Omaña

Department of Human Anatomy, School of Medicine

Universidad Autónoma de Nuevo León

Ave. Madero y Dr. Aguirre Pequeño s/n.

Col. Mitras Centro

Monterrey, N.L.

C.P. 64460

MEXICO

Phone number: 8183 294-171

Fax: 8183 477-790

Email:rod_omana@yahoo.com

Received: 28-09-2011

Accepted: 16-06-2012 